\title{
FENOLLOSA: DA EXEGESE DO IDEOGRAMA ÀS VANGUARDAS
}

\section{FENOLLOSA: FROM THE EXEGESIS OF THE IDEOGRAM TO THE VANGUARDS}

\author{
Márcio de Lima DANTAS ${ }^{1}$ \\ Francisco Freire de AMORIM ${ }^{2}$
}

\begin{abstract}
RESUMO: Partindo das considerações do filósofo norte-americano Ernest Francisco Fenollosa sobre os caracteres chineses, apresentamos, em nossa investigação, pontos de vista sobre problemas da poética ocidental, bem como possíveis soluções para traduções. Entre a possibilidade de uma mitopoética e a existência de uma escrita ligada às estruturas da natureza, analisa-se o surgimento de uma vanguarda artística influenciada pelo Oriente.
\end{abstract}

PALAVRAS-CHAVE: Caracteres chineses; Fenollosa; vanguardas poéticas.

ABSTRACT: Starting from the considerations of the American philosopher Ernest Francisco Fenollosa about the Chinese characters, we present, in our investigation, some opinions about problems

\footnotetext{
${ }^{1}$ Professor Doutor do Programa de Pós Graduação em Estudos da Linguagem - Universidade Federal do Rio Grande do Norte (UFRN) - Lagoa Nova - CEP 59078-970 - Natal - RN - Brasil - E-mail: 7marciodantas7@gmail.com

${ }^{2}$ Mestrando em Literatura Comparada do Programa de Pós Graduação em Estudos da Linguagem - Universidade Federal do Rio Grande do Norte (UFRN) - Lagoa Nova - CEP 59078-970 - Natal - RN - Brasil - E-mail: ffasegundo@hotmail.com
} 
DANTAS, M. L.; AMORIM, F. F. Fenollosa: da exegese do ideograma às vanguardas

of the Western poetic and some possible solutions to translations. Amidst the possibility of a mythopoetic and the existence of a writing related to the nature's structures, we analyse the emergence of an artistic vanguard influenced by East.

KEYWORDS: Chinese characters; Fenollosa; poetic vanguards.

\section{Introdução}

Ao se depararem com o problema da tradução poética da língua ideográfica chinesa, artistas e teóricos têm buscado as mais diversas e, por vezes, contraditórias soluções. De fato, a questão não é simples e, nos últimos cem anos, vem dividindo linguístas, sinólogos e poetas em trincheiras nem sempre transponíveis. Uma dessas soluções tem sido, porém, frequentemente retomada por quem quer que se depare com essas discussões. Trata-se daquela encontrada pelo filósofo e orientalista norte-americano Ernest Francisco Fenollosa (1853-1908), em seu ensaio The Chinese written character as a médium for poetry, e retomada por algumas das correntes estéticas mais significativas do século XX.

Antes de prosseguir com qualquer exposição, é preciso delimitar qual, de fato, é o problema que pretendemos examinar. Um simples exame de um texto escrito em caracteres chineses já revela, mesmo ao leigo, o abismo que existe entre um sistema ideográfico, como o oriental, e um sistema fonético-alfabético de escrita, como os que caracterizam as línguas ocidentais. Deter-se no exame, então, revela ainda mais perplexidades para qualquer estudioso. Observemos o fato, por exemplo, de que o mesmo sistema de caracteres serve como código escrito para povos de línguas diversas, como o chinês, o japonês, o coreano e o vietnamita. Estaríamos diante de um instrumento de comunicação universal, acessível a povos de linguagem oral díspar? 
Foi com essa possibilidade que trabalharam os primeiros estudiosos ocidentais dos caracteres chineses, no século XVII. Entre eles, o filósofo Leibniz (ano aqui vamos ter que deixar sem o ano), que acreditou encontrar, em tal sistema, uma resposta para sua busca por um código abstrato que servisse de língua universal. 0 pensador alemão via nesse grupo de ideogramas uma forma racional de comunicação que funcionaria independentemente de qualquer tipo de oralidade. Mas o que Leibniz enxergou na escrita chinesa foi sua artificialidade, seu jogo abstrato de representação. Essa seria uma forma de escrita inventada por uma sociedade evoluída, para fins unicamente intelectuais. A expressão ideograma passou a designar os caracteres chineses, na Europa, devido a essa suposição de que se tratava de um sistema unicamente gráfico, sem qualquer relação com uma linguagem fônica.

0 fato é que nos séculos seguintes ficou claro para os estudiosos que a escrita chinesa não era apenas um código gráfico abstrato, mas possuía relação direta com a língua falada. Os idealistas, porém, prosseguiram com seus estudos, tentando encontrar na pictografia uma explicação para o estranho fenômeno dos ideogramas. Logo, eruditos chegaram à conclusão de que os caracteres representavam, de alguma forma, os objetos ou as ideias que eles designavam, ou pelo menos os representavam originalmente. A descoberta arqueológica, no século XIX, de um conjunto de inscrições arcaicas em ossos e carapaças de tartaruga reforçou a suposição de uma língua fóssil preservada, que possui relações diretas com suas formas contemporâneas. Estava aberta a era da leitura pictográfica da escrita chinesa, que encontraria seu auge no trabalho de Fenollosa.

Ernest Francisco Fenollosa nasceu em 1853, na cidade norte-americana de Salem. Ainda jovem, convidado por autoridades japonesas para dar aula sobre história da filosofia moderna, embarcou para o oriente, onde desenvolveu uma respeitável carreira, não apenas como divulgador da cultura europeia, mas como estudioso e redescobridor das tradições artísticas nipônicas. A bagagem adquirida em seus anos japoneses 
foi suficiente para que o filósofo desenvolvesse seu mais influente trabalho, o já citado ensaio The Chinese written character as a médium for poetry, deixado apenas manuscrito, mas publicado postumamente pelo poeta Ezra Pound, em 1919. 0 texto de Fenollosa estava fadado, então, a transformar-se em um dos pilares da poética do século XX. Primeiro por sua influência sobre a obra do próprio Pound, depois por sua extensão sobre toda uma vanguarda artística que culminaria com o movimento Concretista surgido no Brasil na década de 50 do século passado.

Mas afinal, o que um sistema tão estranho a um ocidental, como é a escrita chinesa, tem a nos ensinar sobre nossas próprias técnicas de composição poética? Eis o problema que, de fato, foi proposto por Fenollosa.

\section{Da mitopoética à paronomásia}

Ao argentino Jorge Luis Borges é muito cara a ideia de que toda palavra é, originalmente, uma metáfora. "Se pegarmos qualquer bom dicionário etimológico (...) e se procurarmos uma palavra qualquer, na certa encontramos uma metáfora enfurnada em alguma parte" (BORGES, 2000, p. 31). 0 escritor cita como exemplo a palavra king, que originalmente era cyning, cujo significado é "um homem que representa a parentela, o povo". Logo, o uso que se faz hoje, em língua inglesa, de king(rei) é, em sua origem, metafórico, embora ninguém considere tal expressão uma metáfora. Tal fato nos sugere que há por trás de qualquer linguagem, mesmo a mais banal e quotidiana, um fundo poético que nos remeteria a uma língua adâmica, a um falar primitivo todo ele composto de tropos, dentre eles, a metáfora. Ora, que linguagem conserva, entre nós, essa qualidade de arranjo de tropos, de busca, por meio das palavras, pelas coisas em si? Justamente a linguagem poética.

Um filósofo que defendeu ideia semelhante e que influenciou bastante o pensamento fenollosiano foi o norte-americano Ralph Waldo Emerson (1803-1882). Diz ele (1966): 
Conquanto esteja esquecida a origem da maioria de nossas palavras, cada uma delas foi, a princípio, um achado e obteve vigência porque, no momento, simbolizava o mundo para o primeiro elocutor e para o ouvinte. Constata o etimologista que a mais morta das palavras foi algum dia uma figura brilhante. A linguagem é poesia fóssil (EMERSON, 1966, p.133).

Bem compreendidas, as palavras de Emerson nos põe em uma pista semelhante à proposta por Borges: por trás da aparente banalidade e arbitrariedade dos signos linguísticos, existe uma mitopoética que retomaria a coisa em si e apenas a poesia pode recuperar essa capacidade criadora da língua. Ora, o que Fenollosa julgou descobrir em suas pesquisas orientais foi justamente esse sistema primitivo no modelo chinês, que conservaria em sua estrutura a referência direta ao mundo ativo das coisas. Por sua picturalidade, a escrita ideográfica traria em si sua etimologia conservada, visível ao leitor, mesmo leigo.

Para Fenollosa, os jogos de combinações da escrita chinesa funcionavam como um registro mnemônico da humanidade, confirmando a hipótese emersoniana da uma língua adâmica.Um ideograma como o de oceano, por exemplo, ao unir o radical de água, à esquerda, ao pictograma de ovelha ou carneiro, à direita, sugere a imagem de um rebanho de ovelhas em movimento. Fica fácil estabelecermos uma relação metafórica entre essa ideia e a imagem de ondas se encrespando no mar, ou seja, de oceano. 0 filósofo via nisso a genial intuição da mente chinesa, que soube encontrar nas imagens e proporções do mundo natural as estruturas fundamentais que formariam a sua escrita.

Na poesia, então, essa qualidade icônica da escrita, que expõe em si uma relação natural (e aqui vale lembrar que essa exposição não é, para Fenollosa, meramente imitativa, mas criativa), irradia-se por novas harmonizações e justaposições, refletindo novas sequências estruturais. "A poesia supera a prosa, sobretudo porque o poeta escolhe, para justapô -las, palavras cujos matizes se misturam em clara e delicada harmonia” 
(FENOLLOSA, 1977, p. 148). Harmonia, matizes: o próprio vocabulário fenollosiano nos sugere as relações fundamentais em arte. Assim, a qualidade pictográfica da escrita chinesa dialoga com a pintura, mas sua distribuição em linhas sobre o papel deve se harmonizar em formas intercambiáveis, como na música. Uma tônica, ou um matiz, se impõe ao verso, resignificando termos que antes pareciam desconexos. No exemplo citado pelo próprio filósofo, no verso, escrito em ideogramas: “O sol se ergue a leste", o ideograma de sol repete-se nos dois ideogramas seguintes (erguer e leste), criando, assim, uma nota dominante para a linha.

Identificar essa qualidade harmoniosa da poesia escrita em caracteres chineses foi a grande contribuição de Fenollosa para o estudo dos ideogramas, mas é importante ressaltar que seu ensaio propõe, em última análise, a aplicação de tal princípio de harmonia à poética ocidental, ou seja, aquela escrita em língua fonético-alfabética. Aqui, não estamos mais no campo da picturalidade, mas da silabação, da música em si. É preciso pensar, então, em novos harmônicos que não os gráficos. É importante ressaltar que o filósofo norte-americano tinha em seu horizonte a poética tradicional, praticada no Ocidente até o século XIX. As experiências "gráficas" em poesia, embora antecipadas por Mallarmé, só viriam a ser feitas no século XX, em grande parte influenciadas pelo próprio Fenollosa e por sua descoberta da escrita chinesa.

Mas onde encontramos esses harmônicos na poesia ocidental? Analisando essa questão sob o ponto de vista fenollosiano, Haroldo de Campos (1977) diz:

Em poesia - adverte Jakobson - toda coincidência fonológica é sentida como um parentesco semântico (e não apenas aquelas coincidências fundamentais etimologicamente, como na "paraquese", mas, de modo amplo, como no caso da "paronomásia" lato sensu, quaisquer similitudes fônicas confrontáveis semanticamente, num processo fecundante geral de pseudo-etimologia ou etimologia poética [...])(CAMPOS, 1977, p.39). 
No exemplo, citado por Campos (1977), no verso do poeta brasileiro Sousândrade ("'Spectros espectadores que surgiam / Vindo ao espectac'lo horrendo horríveis de palor"), encontramos esse matiz irradiador de significados que espelha, pela paronomásia, sentidos que não estão nas palavras isoladas, mas na ressonância do verso. Assim, encontramos “"spectros" em "espectador", e a assonância proposta em "horrendo", "horríveis", "palor", cria (ou descobre) uma nova família de palavras, unidas por essa pseudo-etimologia de que nos fala Campos.

Ora, mas o que a poética ocidental faz por meio de jogos fônicos é exatamente o que a poesia escrita em caracteres chineses nos propõe em nível icônico: esta contaminação irradiadora de significados, que só é possível na linguagem poética, em busca constante pela raiz estrutural das coisas. É na paronomásia, mais do que na metáfora, que encontramos a mitopoética, a língua original do homem.

\section{A tradução fenollosiana}

Essa gramática da língua poética, segundo Fenollosa, recria a gramática da natureza. É nessa descoberta estrutural das palavras que o filósofo julga encontrar a chave para uma leitura ocidental dos caracteres chineses. Diz Fenollosa (1977):

Já não é suficiente mostrar que a poesia chinesa se aproxima mais dos processos da Natureza em virtude de sua forma vívida, da riqueza dessa forma figural? Se procurarmos acompanhá-la em inglês, teremos de usar palavras altamente carregadas, palavras cuja sugestão vital esteja em interação, tal como a Natureza. As sentenças devem ser como o entremear das franjas de bandeiras flutuantes, ou como as cores de muitas flores misturadas no resplendor único de uma campina (FENOLLOSA, 1977, p. 148).

É bem verdade que Fenollosa reconheceu a superioridade da escrita chinesa nesse aspecto. Embora cite o exemplo de Shakespeare como modelo de uma língua irradiadora e carregada de potências, o ideograma 
realiza esse propósito, digamos, natural da língua pela sua simplicidade pictórica. As constantes metáforas e os, por vezes, grosseiros jogos sonoros da poesia ocidental não alcançam o oriente em sua espontaneidade. Ao traduzir um verso escrito em ideogramas para uma língua ocidental, o poeta quase sempre é obrigado a optar entre a simples reprodução literal do que está sendo dito e a completa reformulação estética do verso. Ao contrário dos sinólogos de seu tempo, Fenollosa não deixou de recomendar o segundo caminho. Mas o que seria essa reformulação estética?

0 filósofo norte-americano encarou a questão da escrita chinesa como uma representação da natureza em seus processos reais, não abstratos. Ora, argumenta Fenollosa, não existe um ser isolado ou um ente abstrato na natureza. Muito menos ações puras, desprovidas de agentes. Da mesma forma, os agentes não existem separados de suas ações. Assim, nossa vista apreende, como sendo uma só coisa, o sujeito e o verbo. Se na escrita fonético-alfabética somos obrigados a encadear sucessões de elementos (sujeito-verbo-predicado), ou criar nomes para entes que não existem concretamente (como leste), na escrita ideográfica estamos livres de tal decomposição ou abstração. 0 leste, por exemplo, só existe se levarmos em consideração determinadas sugestões do espaço que se dão em um mundo real, composto de entes. Os chineses resolvem tal questão representando leste com um ideograma que combina o signo de sol enredado nos galhos de um signo de árvore. Sol e árvore: entes reais.Se não existissem entes, qualquer orientação espacial seria inalcançável, assim como seria impossível o conceito de "leste".

Vejamos como funcionaria uma tradução fenollosiana levando-se em consideração todas essas questões. Partindo de um poema de Li-Tai-Po, encontramos o seguinte verso, traduzido para o inglês por Ezra Pound: Mind like a floating wide cloud. 0 original, escrito em caracteres chineses, nada mais faz do que suceder os ideogramas de flutuante, nuvem, viajar, o sufixo tzu e o carácter de ânimo. Importa aqui encontrar a tonalidade, a dominante pictográfica do verso original.

Haroldo de Campos nota que essa dominante é o radial no 39, que, no 
chinês clássico representa menino. Ele aparece no primeiro ideograma, para flutuante, na forma de uma criança sob as garras de um pássaro, como que sendo protegida. À esquerda do mesmo ideograma, vemos o radical para água. Assim, a imagem da criança protegida, sobre águas, sugere-nos o verbo advérbio flutuante ("floating"). No terceiro carácter, encontramos o mesmo radical no 39, agora ao lado da forma abreviada do pictograma de pé, e sob a forma de um homem que nada. Viajar seria, portanto, como movimentar-se sobre águas, harmonizando-se com o primeiro pictograma, para flutuante. Por fim, o mesmo menino aparece, em sua inteireza, sob a forma do sufixo $t z u$, articulado na terceira tonalidade do chinês clássico. Nesse menino que percorre em todo o verso ideográfico, Pound foi encontrar o ente real que representaria os movimentos do pensamento, que se estende como que sobre as águas da mente. Não podemos deixar de observar a tônica sonora do verso poundiano, onde mind torna possível wide, e floating nos antecipa cloud.

\section{0 problema sinológico}

O ensaio de Fenollosa afetou profundamente Ezra Pound e, consequentemente, toda a vanguarda poética ocidental. Mesmo assim, não deixou de encontrar seus críticos entre os eruditos sinólogos. Apontado como ingênuo, bem como fruto de uma idealização dos caracteres chineses, essa visão dos ideogramas foi desconstruída, nas décadas seguintes, por seus detratores. Um deles, Yu-Kuang Chu (1977), argumenta que a pictografia é apenas um dos princípios formadores dos caracteres chineses. Além disso, a crescente estilização dos ideogramas em sua evolução histórica torna difícil uma precisa reconstrução da escrita original e, dessa maneira, suas reais relações com os seres representados. Por fim, Yu-Kuang Chu alerta para o fato de que, para o chinês contemporâneo, a leitura de um texto ideográfico não é diferente da leitura que um ocidental faz de sua língua fonético-alfabética: resta apenas a convenção dos signos, sem nenhum reconhecimento de raízes etimológicas ou me- 
táforas visuais. Outro problema identificado no ensaio é que, embora Fenollosa não tenha ignorado a relação entre a escrita e a fonética chinesa, é fato que o mesmo passou superficialmente pelo elemento sonoro, que é fundamental para a construção de muitos caracteres.

Mas, embora não tenha encontrado respaldo entre os especialistas, Fenollosa teve seu pensamento aplicado por alguns dos mais inovadores poetas do século XX. 0 próprio Haroldo de Campos, por exemplo, não ignorando o argumento sinológico, defende que o ensaio The Chinese written character as a médium for poetry só pode ser entendido sob a ótica da linguagem poética, tal qual descrita por Roman Jakobson (ano1969). É fato que o poeta e ensaísta brasileiro aplicou com êxito vários elementos fenollosianos em sua obra.

Por fim, não podemos esquecer que o próprio destino do texto manuscrito original nos diz muito sobre como ele deve ser lido. Basta sabermos que, de posse do material deixado pelo marido Ernest, a viúva Mary Fenollosa preferiu confiá-lo não a eruditos ou sinólogos, mas a um jovem poeta, hoje mundialmente conhecido como Ezra Pound.

\section{REFERÊNCIAS}

ALLENTON, V. Escrita chinesa. Porto Alegre: L\&PM, 2012.

BORGES, J. L. Esse ofício do verso. São Paulo: Companhia das Letras, 2000.

CAMPOS, H. Ideograma, anagrama, diagrama: uma leitura de Fenollosa. In: __ (Org). Ideograma: lógica, poesia, linguagem. São Paulo: Cultrix, 1977.

CHU, YYu-Kuang. Interpretação entre linguagem e pensamento em chinês. In: CAMPOS, H.(Org). Ideograma: lógica, poesia, linguagem. São Paulo: Cultrix, 1977. 
DANTAS, M. L.; AMORIM, F. F. Fenollosa: da exegese do ideograma às vanguardas

EMERSON, R. W. Ensaios. São Paulo: Cultrix, 1966.

FENOLLOSA, E. F. Os caracteres da escrita chinesa como instrumento para a poesia. In CAMPOS, H. (Org). Ideograma: lógica, poesia, linguagem. São Paulo: Cultrix, 1977.

JAKOBSON, R. Linguística e comunicação. Trad. de I. Blikstein e J. P. Paes. São Paulo: Cultrix/EDUSP, 1969. 